\title{
Insulin restores neuronal nitric oxide synthase expression and function that is lost in diabetic gastropathy
}

\author{
Crystal C. Watkins, ${ }^{1}$ Akira Sawa, ${ }^{1}$ Samie Jaffrey, ${ }^{1}$ Seth Blackshaw, ${ }^{1}$ Roxanne K. Barrow, ${ }^{1}$ \\ Solomon H. Snyder, ${ }^{1,2,3}$ and Christopher D. Ferris ${ }^{1,4}$ \\ ${ }^{1}$ Department of Neuroscience, \\ ${ }^{2}$ Department of Pharmacology and Molecular Sciences, \\ ${ }^{3}$ Department of Psychiatry and Behavioral Sciences, and \\ ${ }^{4}$ Division of Gastroenterology, Department of Medicine, The Johns Hopkins University, School of Medicine, \\ Baltimore, Maryland, USA \\ Address correspondence to: Christopher D. Ferris, Department of Medicine, Division of Gastroenterology, \\ C-2104 Medical Center North, Vanderbilt University Medical Center, Nashville, Tennessee 37232-2279, USA. \\ Phone: (615) 343-4747; Fax: (615) 343-6229; E-mail: christopher.ferris@mcmail.vanderbilt.edu.
}

Received for publication August 27, 1999, and accepted in revised form June 27, 2000.

\begin{abstract}
Gastrointestinal dysfunction is common in diabetic patients. In genetic (nonobese diabetic) and toxin-elicited (streptozotocin) models of diabetes in mice, we demonstrate defects in gastric emptying and nonadrenergic, noncholinergic relaxation of pyloric muscle, which resemble defects in mice harboring a deletion of the neuronal nitric oxide synthase gene ( $n N O S)$. The diabetic mice manifest pronounced reduction in pyloric nNOS protein and mRNA. The decline of nNOS in diabetic mice does not result from loss of myenteric neurons. nNOS expression and pyloric function are restored to normal levels by insulin treatment. Thus diabetic gastropathy in mice reflects an insulin-sensitive reversible loss of nNOS. In diabetic animals, delayed gastric emptying can be reversed with a phosphodiesterase inhibitor, sildenafil. These findings have implications for novel therapeutic approaches and may clarify the etiology of diabetic gastropathy.
\end{abstract}

J. Clin. Invest. 106:373-384 (2000).

\section{Introduction}

Diabetes mellitus is a common disorder worldwide and may affect seven million people in the United States, indicating a prevalence of $2-3 \%(1,2)$. Diabetes is a chronic disorder resulting in significant complications including vascular diseases, peripheral and autonomic neuropathies, retinopathy, and gastrointestinal dysfunction (2). Gastrointestinal dysfunction may occur in as many as $75 \%$ of diabetic patients (3-6) and include diabetic gastropathy (7), a syndrome of delayed gastric emptying, leading to nausea, vomiting, abdominal pain, and early satiety $(5,6,8)$. Although the mechanism through which diabetics develop gastropathy is unclear, it may involve perturbation in the normal relaxation of the pyloric sphincter, as this step is required in the coordinated activity of the proximal stomach, antrum, pylorus, and duodenum that results in gastric emptying $(9,10)$. Evidence suggests that impaired pyloric inhibition may contribute to gastropathy in diabetics (11).

Nitric oxide (NO) has been found to have an important function as a neurotransmitter in the intestine including the stomach and pylorus (12-14). A critical role for NO in gastropyloric function was established by the findings of pyloric hypertrophy and gastric dilation in mice harboring a targeted genomic deletion of neuronal nitric oxide synthase $\left(n \mathrm{NOS}^{-/-}\right)$(15). Loss of pyloric nNOS is associated with gastric outflow obstruction as occurs in infantile hypertrophic pyloric stenosis $(16,17)$. Exogenous NO reduces both the number and amplitude of isolated pyloric pressure waves in normal humans (18). NO donors also alter the distribution of liquid glucose within the stomach and may slow gastric emptying, perhaps by reducing tone in the proximal stomach (19). Endogenous NO may inhibit gastric emptying in humans $(20,21)$, although in animal models, nNOS inhibition delays gastric emptying (22-24).

Studies suggest that nNOS dysregulation may contribute to gastropyloric dysfunction in animal models of diabetes. Streptozotocin-induced (STZ-induced) diabetes results in a modest diminution of NO-dependent relaxation of gastric muscle strips in rats (25) and a modest decrease in nNOS protein expression in the antrum of the stomach (26). The stomachs of spontaneously diabetic rats have decreased NO-mediated relaxation of gastric muscle strips and attenuated expression of nNOS protein and mRNA (27). These studies suggest that nNOS expression may be disrupted in diabetes. However, because blood glucose levels were not corrected in these studies, the mechanism and the functional consequences of the loss of nNOS expression remain obscure.

In the present study, we evaluate the role of nNOS in gastropyloric function by monitoring gastric emptying and pyloric neurophysiology in ex vivo organ bath preparations using mice with targeted genomic deletion of $n N O S$. We report delayed gastric emptying and 
a loss of $\mathrm{NO}$-mediated nonadrenergic, noncholinergic (NANC) relaxation in the pylorus of $n \mathrm{NOS}^{-/-}$mice. Using two models of diabetes in mice, we find that diabetic mice develop delayed gastric emptying and a loss of NO-mediated NANC relaxation in the pylorus that resembles the phenotype of $n \mathrm{NOS}^{-/-}$mice. nNOS protein and mRNA are depleted in pyloric myenteric neurons of diabetic mice consistent with a lack of NOmediated pyloric relaxation. Insulin treatment reverses the abnormal physiology of diabetic mice and restores pyloric nNOS protein and mRNA. Treatment of diabetic animals with sildenafil, a cGMP phosphodiesterase inhibitor that augments NO signaling, reverses delayed gastric emptying. Accordingly, the key features of diabetic gastropathy in mice reflect a reversible downregulation of $\mathrm{nNOS}$.

\section{Methods}

Animals. Mice were allowed free access to food and water except when fasted, as indicated for experiments. The weights and serum glucose levels of groups of animals used for experiments are given in Table 1. Wildtype mice (C57BL/6) were purchased from The Jackson Laboratory (Bar Harbor, Maine, USA). $n N^{-/-}$mice were obtained following targeted genomic deletion of $n N O S$ (15) and have the genetic background of C57BL/6 mice (28). For STZ-induced diabetes, adult male mice (C57BL/6) were injected intraperitoneally with a single dose of STZ $(200 \mathrm{mg} / \mathrm{kg}$ in $0.1 \mathrm{M}$ sodium citrate) as described elsewhere (29), whereas control mice were injected with an equal volume of vehicle (sodium citrate). STZ-treated mice were used for experiments 8 weeks after STZ injection. After STZ treatment, serum glucose levels were monitored weekly by tail vein sampling of animals fasted for 12 hours with the Accu-Check Easy Blood Glucose Monitor (model 788; Boehringer Mannheim, Indianapolis, Indiana, USA). The average serum glucose levels for wild-type animals and the STZ diabetic mice 8 weeks after injection were $99 \mathrm{mg} / \mathrm{dL}$ and $388 \mathrm{mg} / \mathrm{dL}$, respectively (Table $1)$. Adult male nonobese diabetic (NOD/LtJ [NOD]) mice were obtained at 8-10 weeks of age (The Jackson Laboratory). Serum glucose levels were also monitored weekly with the Accu-Check monitor. NOD-prediabetic mice and NOD-diabetic mice had average serum glucose levels of $88 \mathrm{mg} / \mathrm{dL}$ and $232 \mathrm{mg} / \mathrm{dL}$, respectively (Table 1). For the indicated experiments, NOD-prediabetic mice were sacrificed at 10 weeks of age after serum glucose levels were confirmed, whereas NOD-diabetic mice were sacrificed at 30-32 weeks of age after elevated serum glucose levels were confirmed.

Insulin treatment was given using LinBit, a sustained-release insulin implant $(0.1 \mathrm{U} / \mathrm{d} / \mathrm{implant}$; LinShin Canada Inc., Toronto, Ontario, Canada). After brief anesthesia with diethyl ether, the insulin implant was quickly immersed in Betadine solution (McKesson, San Francisco, California, USA) and implanted subcutaneously with a 12-gauge needle. Serum glucose levels were monitored, and insulin-treated animals were used for experiments after 12 hours or 1 week of insulin therapy, as indicated. The serum glucose levels after 1 week of insulin treatment are shown (Table 1), as are the serum glucose levels after 12 hours of insulin treatment (see Figure 2b).

As indicated, insulin-treated diabetic mice were treated with the nNOS inhibitor 7-nitroindazole (7-NI; Lancaster, Wyndham, New Hampshire, USA) by two intraperitoneal injections $(50 \mathrm{mg} / \mathrm{kg})$ of a suspension in sesame oil (Sigma Chemical Co., St. Louis, Missouri, USA) given 24 hours and 30 minutes before determination of gastric emptying. In other experiments, NOD-diabetic and STZ-diabetic mice were treated with sildenafil ( $1 \mathrm{mg} / \mathrm{kg}$ in water; Pfizer, Groton, Connecticut, USA) by intraperitoneal injection 20 minutes before determination of gastric emptying. For all experiments, control animals were similarly injected with vehicle (either sesame oil or water).

Gastric emptying. Gastric emptying of liquids was determined as described previously (30). For any experiments using diabetic mice, serum glucose levels of all animals were confirmed immediately before monitoring gastric emptying. Adult mice were sedated briefly (<30 seconds) with diethyl ether. Mice fully recovered from sedation in less than 1 minute. During brief sedation, oralgastric intubation was accomplished with a 21-gauge needle fitted with a thin plastic catheter $(8 \mathrm{~cm}$ in length). Then, $0.2 \mathrm{~mL}$ of $1 \mathrm{mg} / \mathrm{mL}$ phenol red-labeled $20 \%$ dextrose (or other solution, if indicated) was instilled into the stomach. Mice were placed in clean, empty cages until the time of sacrifice. At the indicated time ( $0-120$ minutes), mice were rapidly sacrificed by cervical dislocation and the stomach was excised. The duodenum was ligated, followed by transverse resection of the lower esophagus, and the stomach was removed from the body cavity. Excised stomachs were homogenized with a polytron (Brinkmann, Westbury, New York, USA) homogenizer in $3 \mathrm{~mL}$ of $95 \%$ ethyl alcohol. After centrifugation $(40,000 \mathrm{~g}$ for 20 minutes), an aliquot of the supernatant was used to determine phenol red content. Standard curve was constructed and found to be linear over the range of $1-20 \mu \mathrm{g}$ of phenol red. Phenol red content was monitored at $410 \eta \mathrm{m}$, at which a single peak of absorbance was observed when extracted with ethanol. Thus, gastric emptying data are presented as the percent of phenol red retained, which is calculated as the mean ( \pm SEM) of several measurements from several animals for each time point as indicated in the figure legends. The time required to empty $50 \%$ of the phenol red containing meal (half-time $\left[\mathrm{t}_{1 / 2}\right]$ ) was derived directly from the graphed data.

Organ bath physiology. Mice were sacrificed by cervical dislocation, and the gastrointestinal tract from the lower esophageal sphincter to the distal duodenum was removed from the body cavity and placed in $\mathrm{Ca}^{2+}$ free Krebs-Henseleit $(\mathrm{KH})$ buffer. The pyloric sphincter muscle was dissected in $\mathrm{Ca}^{2+}$-free $\mathrm{KH}$ and mounted between two L-shaped tissue hooks. The ex vivo preparations were then placed in $25-\mathrm{mL}$ chambers 
containing $\mathrm{KH}$ buffer (Sigma Chemical Co.) at $37^{\circ} \mathrm{C}$ and continuously bubbled with $95 \% \mathrm{O}_{2}, 5 \% \mathrm{CO}_{2}$. Tension was monitored with an isometric force transducer and recorded with a chart recorder. For routine experiments, pylori were equilibrated in $\mathrm{KH}$ buffer for 1 hours with $4.9 \mathrm{mN}$ of tension applied. Then, pylori were pretreated with atropine $(1.0 \mu \mathrm{M})$, propanolol $(1.0 \mu \mathrm{M})$, and indomethacin $(10.0 \mu \mathrm{M})$ for 30 minutes to block cholinergic-, adrenergic-, and prostaglandinmediated responses, respectively. Ex vivo preparations of pylori have regular phasic contractions but do not develop significant spontaneous tone (tonic contraction) that would allow the direct measurement of relaxation. Thus, precontraction of the pyloric muscles with substance P (SP) was used to generate tonic muscle contraction and allow the measurement of relaxation. Pylori were contracted with $0.1 \mu \mathrm{M}$ SP, and those specimens demonstrating a sustained tonic contraction were used for experiments. NANC relaxations were induced $10-20$ seconds after contraction with SP by electrical field stimulation (EFS; $40 \mathrm{~V}, 2-10 \mathrm{~Hz}, 5$ ms pulse for a duration of 5 or 2 seconds, as indicated). For quantitative determination of relaxation, we used several pylori from any given treatment condition, as indicated in the figure legends, and used the relaxation obtained from the first EFS under NANC conditions. In some experiments, pylori were stimulated first with $10 \mathrm{~Hz}$ followed by 5 and then $2 \mathrm{~Hz}$, whereas in others, the order of stimulation was reversed. In wild-type pylori, responses to EFS were similar regardless of the order of stimulation. In other experiments, we observed similar responses to 2,5 , or $10 \mathrm{~Hz}$ given as single stimuli after SP contraction. To confirm the role of neuronal depolarization in evoking NANC relaxations, tetrodotoxin (TTX; $0.1 \mu \mathrm{M}$; Research Biochemical, Natick, Massachusetts, USA) was used. The NO dependence of NANC relaxations was confirmed by incubation with either $0.1 \mathrm{mM} \mathrm{N}$ nitro-L-arginine (L-NNA; Sigma Chemical Co.) or 0.1 mM 7-NI for 30 minutes before EFS.

Immunohistochemistry. For nondiabetic studies, wildtype animals or 10-week-old NOD-prediabetic animals were used. For diabetic studies, we used animals 8 weeks after STZ injection (STZ diabetic) or 30-week-old NOD mice (NOD-diabetic). Pylori or other tissues were dissected and immediately imbedded (Tissue-Tek OCT 4583; Sakura Finetek Inc., Torrence, California, USA) and placed in dry ice and allowed to freeze. Routine sections $(10 \mu \mathrm{m})$ were cut using a cryostat $\left(-19^{\circ} \mathrm{C}\right.$; Leica Microm, Allendale, New Jersey, USA). For immunostaining, slides were fixed for 5 minutes in $4.0 \%$ paraformaldehyde, washed in PBS, and permeabilized with $0.1 \%$ Triton $\mathrm{X}-100$ in PBS. Then, slides were incubated overnight at $4{ }^{\circ} \mathrm{C}$ with primary antibodies as indicated: anti-nNOS (1:8,000; DiaSorin, Stillwater, Minnesota, USA), anti-synaptophysin (1:500; Sigma Chemical Co.), anti-VIP (1:4,000; Calbiochem-Novabiochem Corp., San Diego, California, USA), and anti-MAP-2 (1:200; Boehringer Mannheim). The anti- gens were visualized using the appropriate secondary antibodies and the Vectastain ABC kit (Vector Laboratories, Burlingame, California, USA).

In situ bybridization. In situ hybridization for $n N O S$ was performed as described previously $(31,32)$.

Western blot analysis. Mouse tissues were homogenized in ice-cold buffer containing $50 \mathrm{mM}$ Tris ( $\mathrm{pH} 7.4$, $25^{\circ} \mathrm{C}$ ), $100 \mathrm{mM} \mathrm{NaCl}, 1 \mathrm{mM}$ EGTA, and protease inhibitors $(4 \mu \mathrm{g} / \mathrm{mL}$ leupeptin, $2 \mu \mathrm{g} / \mathrm{mL}$ antipain, 2 $\mu \mathrm{g} / \mathrm{mL}$ chymostatin, $2 \mu \mathrm{g} / \mathrm{mL}$ pepstatin, and $1 \mathrm{mM}$ PMSF). After centrifugation (15 minutes, 16,000 g), the supernatants were collected and protein content was determined (Coomassie protein assay; Pierce Chemical Co., Rockville, Illinois, USA). Samples (50 $\mu \mathrm{g}$ protein) were subjected to SDS-PAGE (4-12\% gradient gel; Bis-tris NuPage; Novex, San Diego, California, USA) and then transferred to PVDF membranes (Immobilon-P; Millipore Corp., Bedford, Massachusetts, USA). For Western blot analysis, blots were incubated in blocking buffer (PBS, $0.1 \%$ Tween-20, $5 \%$ nonfat milk) for 30 minutes at $25^{\circ} \mathrm{C}$. Then, the blots were incubated in blocking buffer with primary antibody (anti-nNOS antibody, MAB1265; Transduction Laboratories, Lexington, Kentucky, USA) at a dilution of 1:1,000 for 1 hour at $25^{\circ} \mathrm{C}$ with gentle agitation, followed by three 5 -minute washes with blocking buffer. Blots were then incubated with secondary antibody (goat anti-mouse IgG; Amersham Life Sciences Inc., Arlington Heights, Illinois, USA) at a dilution of $1: 5,000$ in blocking buffer for 30 minutes at $25^{\circ} \mathrm{C}$, followed by three 5 -minute washes with blocking buffers and then two 5-minute washes with PBS. Immunoreactive proteins were visualized using enhanced chemiluminescence (Renaissance Western Blot Chemiluminescence Reagent Plus; NEN Life Science Products Inc., Boston, Massachusetts, USA).

Statistical analysis. Data were analyzed using GraphPad Prism software (version 2.01; GraphPad Software Inc., San Diego, California, USA). Significance was analyzed using a paired, two-tailed, Student's $t$ test, and, unless otherwise indicated, data are presented as mean values $( \pm$ SEM). As indicated, single comparisons of groups of experimental mice were made to the appropriate control group.

\section{Results}

$n \mathrm{NOS}^{-/-}$mice have delayed gastric emptying and lack pyloric NANC relaxation. The pyloric hypertrophy and gastric dilation of $n \mathrm{NOS}^{-/-}$mice suggests a key role for $\mathrm{NO}$ in pyloric function (15). nNOS is expressed throughout the stomach, pylorus, and intestine (33-35), and all of these tissues contribute to the coordinated regulation of gastric emptying (10) in different ways. Thus, we wanted to determine the overall functional effect of genomic deletion of $n N O S$ on gastropyloric physiology in $n \mathrm{NOS}^{-/-}$mice. To address this, we adapted a spectrophotometric method to measure gastric emptying of liquid meals in mice $(30,36)$. In these experiments, mice underwent oral-gastric intubation with a small catheter followed by instillation of a liquid containing a known 
quantity of phenol red. At appropriate times thereafter, the phenol red remaining in the stomach was quantified spectrophotometrically. Saline empties rapidly with a $t_{1 / 2}$ of 8 minutes, whereas $10 \%$ and $20 \%$ dextrose empty more slowly $\left(t_{1 / 2}=24\right.$ and 32 minutes for $10 \%$ and $20 \%$ dextrose, respectively), reflecting a normal physiological slowing of gastric emptying in response to increased caloric load (Figure 1a). In $n N^{-/-}$mice, we observe a substantial delay in gastric emptying for saline $\left(t_{1 / 2}=34\right.$ minutes), $10 \%$ dextrose ( $\mathrm{t}_{1 / 2}=50$ minutes $)$, and $20 \% \mathrm{dex}$ trose $\left(t_{1 / 2}=75\right.$ minutes, Figure $\left.1 b\right)$. Thus, gastric emptying is delayed in $n N^{-1-}$ mice, consistent with a key role for $\mathrm{nNOS}$ in gastric emptying.

Because localized pyloric contractions can obstruct gastric outflow $(9,10)$, impaired pyloric relaxation may account for delayed gastric emptying in $\mathrm{nNOS}^{-/-}$mice. To assess this possibility, we used ex vivo organ bath preparations of mouse pylori. $n \mathrm{NOS}^{-/-}$pylori have normal responses to acetylcholine (ACh), substance $\mathrm{P}(\mathrm{SP})$, and sodium nitroprusside (SNP) (data not shown), suggesting that smooth muscle function is not affected by loss of nNOS. Under NANC conditions, pylori were precontracted with $0.1 \mu \mathrm{M} \mathrm{SP}$, and NO-dependent relaxation was elicited by electrical field stimulation. Wild-type pylori demonstrate substantial NANC relaxation in response to EFS (Figure 1, $\mathrm{c}$ and d). This relaxation is mediated by $\mathrm{NO}$ as it is blocked by nNOS inhibitors, including $0.1 \mathrm{mM} \mathrm{L-NNA}$ and $0.1 \mathrm{mM}$. Under the same conditions, NANC relaxation is nearly abolished in $n \mathrm{NOS}^{-/-}$pylori (Figure 1, c and d). EFSinduced relaxations in wild-type pylori are completely blocked by $0.1 \mu \mathrm{M}$ TTX, consistent with a neuronal source of NO. These results suggest that nNOS-derived $\mathrm{NO}$ accounts for NANC relaxation in the pylorus and that loss of NO-mediated NANC relaxation causes delayed gastric emptying.

Diabetic mice have delayed gastric emptying and decreased NO-dependent NANC relaxation similar to those of $n \mathrm{NOS}^{-/-}$ mice. The delayed gastric emptying observed in the $n N^{-1-}$ mice is similar to human diabetic gastropathy (4-6, 37-39). In addition, previous reports have suggested that $\mathrm{nNOS}$ expression may be altered in diabetic rats (25-27). To ascertain whether nNOS plays a role in diabetic gastropathy, we evaluated gastropyloric
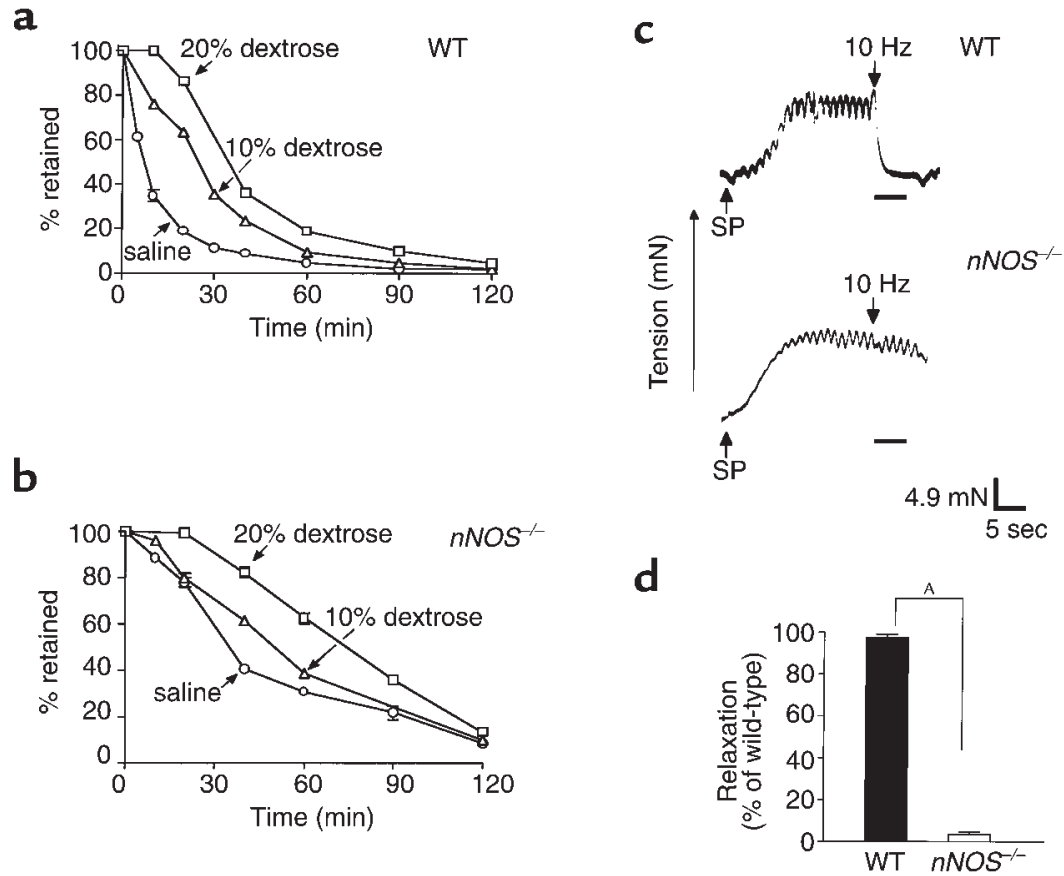

\section{Figure 1}

$n \mathrm{NOS}^{-/-}$mice have delayed gastric emptying and loss of NO-dependent NANC relaxation. Gastric emptying in (a) wild-type (WT) mice and (b) $n \mathrm{NOS}^{-/-}$mice. As described in Methods, phenol red-labeled saline (circles), 10\% dextrose (triangles), or 20\% dextrose (squares) was instilled into the stomachs of groups of mice, five to ten animals for each time point. The mice were sacrificed at the indicated times to determine the fraction of phenol red remaining in the stomachs as a measure of gastric emptying. Individual data points represent the mean ( \pm SEM) for five to 10 determinations at each time point derived from groups of individual mice. In some instances, the error bars are small and contained within the symbol. The delay in gastric emptying observed in response to increased caloric content is consistent with known gastric physiology and is preserved in $n \mathrm{NOS}^{-/-}$mice. (c) EFS-evoked NANC relaxations were monitored from wild-type and $n \mathrm{NOS}^{-/-}$pylori as described (see Methods). After precontraction with SP $(0.1 \mu \mathrm{M})$, wild-type pylori demonstrate relaxation (>95\%) in response to EFS $(40 \mathrm{~V}, 10 \mathrm{~Hz}, 5 \mathrm{~ms}$ pulse for a duration of 5 seconds), whereas relaxation is nearly absent in $n N^{-1-}$ pylori $(<5 \%)$. All EFS-evoked relaxations were blocked with $0.1 \mu \mathrm{M} T \mathrm{TX}$ and the nNOS inhibitors L-NNA $(0.1 \mathrm{mM})$ and 7-NI $(0.1 \mathrm{mM})$. The examples shown are from a representative experiment. (d) Quantification of NANC-induced relaxations in response to EFS for wild-type and $n N^{\prime-1-}$ pylori. Several pylori representing wild-type and $n N^{-1} S^{-/-}$mice were used to quantitatively analyze the degree of NANC relaxation in response to EFS. Data shown are the means $( \pm$ SEM) of several determinations for each group of mice ( $n=20$ for wild-type and 10 for $n N^{-1-}$ pylori). ${ }^{\text {Ap }}<0.01$ compared with wild-type specimens. 
a

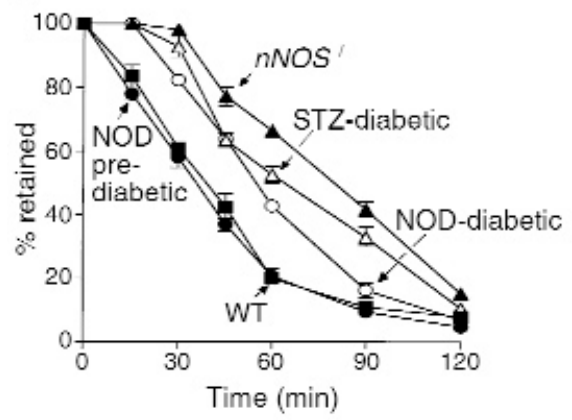

b

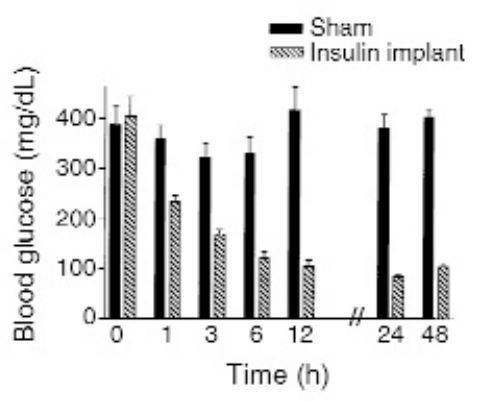

C

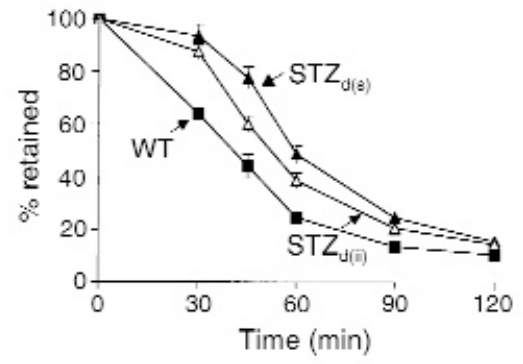

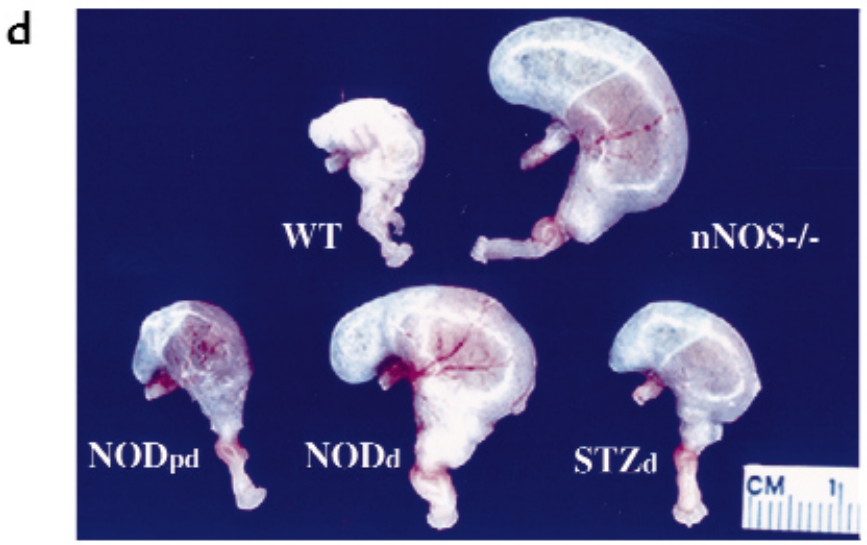

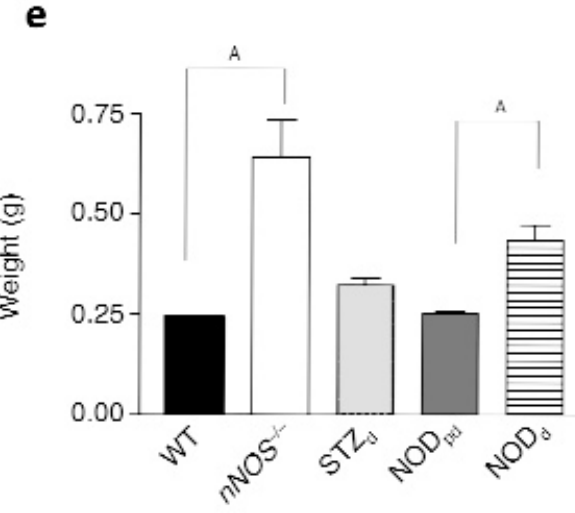

Figure 2

Diabetic mice have delayed gastric emptying that is not due to hyperglycemia and enlarged stomachs. (a) Gastric emptying (20\% dextrose) in diabetic mice. NOD-prediabetic mice (filled circles), age 10 weeks, have gastric emptying rates similar to wild-type mice (filled squares). STZdiabetic mice (open triangles) and NOD-diabetic mice (open circles) exhibit significantly delayed gastric emptying, similar to that of $n N^{\prime-} S^{--}$ mice (filled triangles). Each data point represents the mean ( \pm SEM) from groups of four to six animals. All diabetic animals exhibit some delay in gastric emptying, and this is reflected in the error bars (SEM) as shown. In some instances, the error bars are small and contained within the symbols. This experiment has been repeated twice with the same results. (b) Serum glucose levels of STZ-diabetic mice after insulin treatment. STZ-diabetic mice were either sham operated $(n=5)$ or treated with subcutaneous placement of an insulin-releasing implant $(n=5$; see Methods). Then, serum glucose levels were determined at the indicated time points. The data shown are the means ( \pm SEM) of five measurements for each time point. Serum glucose levels decline to around $100 \mathrm{mg} / \mathrm{dL}$ by 12 hours and remain at similar levels for 48 hours. (c) Gastric emptying in STZ-diabetic mice after 12 hours of insulin treatment. STZ-diabetic mice were either sham operated (STZ $\left.\mathrm{d}_{(\mathrm{s})}\right)$ or treated with subcutaneous placement of an insulin-releasing implant $\left(\mathrm{STZ} \mathrm{d}_{\mathrm{d}(i)}\right) 12$ hours before determination of gastric emptying. The data shown are the means $\left( \pm\right.$ SEM) for five to seven measurements per time point. (d) Stomachs excised from wild-type, NOD-prediabetic (NOD $\left.{ }^{\text {pd }}\right), n N O S^{-/-}$, NOD-diabetic $\left(N O D_{d}\right)$, and STZ-diabetic $\left(S T Z_{d}\right)$ mice were photographed to demonstrate the enlargement of the stomach in NOD-diabetic mice. The pictures are representative of five to eight specimens examined for each group of animals. (e) Stomachs from wild-type, NOD-prediabetic, $n \mathrm{NOS}^{-/-}$, NOD-diabetic, and STZ-diabetic mice were weighed after fasting for 4 hours. Data shown are the means ( \pm SEM) for five specimens in each group. The stomachs from the NOD-diabetic and $n \mathrm{NOS}^{-1-}$ mice weighed significantly more than those from wild-type mice. AP $<0.05$ for $n N^{-1-}$ stomachs compared with wild-type and for NOD-diabetic specimens compared with NOD-prediabetic.

function in two models of diabetes in mice. NOD mice develop diabetes spontaneously, around 14 weeks of age, through autoimmune destruction of the pancreatic $\beta$ cells (40). Thus, young NOD mice (NOD-prediabetic) have normal insulin and glucose levels, although older NOD-diabetic mice have insulin-deficient diabetes. A second model of diabetes in mice uses STZ, a toxic glucose derivative selectively taken up by pancreatic $\beta$ cells (29). We induced diabetes with a single injection of STZ $(200 \mathrm{mg} / \mathrm{kg}$; as discussed in Methods) and studied the gastropyloric function of the STZdiabetic mice after 8 weeks. NOD-prediabetic mice have normal gastric emptying rates, similar to agematched, wild-type controls, whereas gastric emptying is markedly delayed in NOD-diabetic mice (Figure 2a).
Like NOD-diabetic mice, STZ-diabetic mice have substantially delayed gastric emptying, resembling that of $n N^{-1-}$ mice (Figure 2a). Thus delayed gastric emptying occurs in two distinct models of diabetes in mice.

Hyperglycemia, including blood glucose levels within the normal postprandial range, can delay gastric emptying in normal and diabetic humans (41-47), although increased pyloric contractions may not contribute to delayed gastric emptying during euglycemia (48). Thus, hyperglycemia alone might explain the delay in gastric emptying observed in diabetic mice. To address this possibility, we treated STZ-diabetic animals with insulin using a subcutaneous implant (see Methods) and monitored serum glucose levels. Glucose levels declined from nearly $400 \mathrm{mg} / \mathrm{dL}$ to approximately $100 \mathrm{mg} / \mathrm{dL}$ by 12 
a

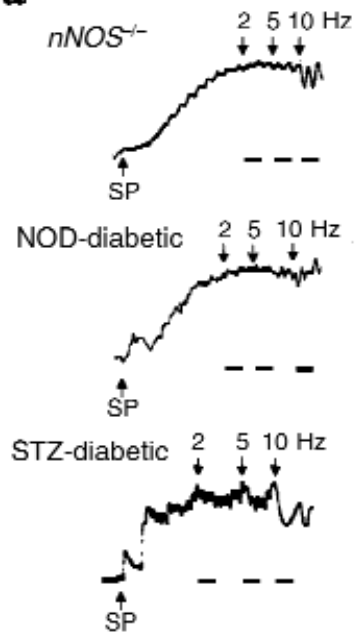

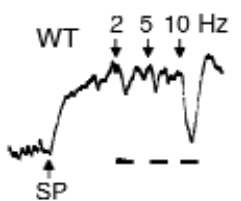

WT $105-2 \mathrm{~Hz}$

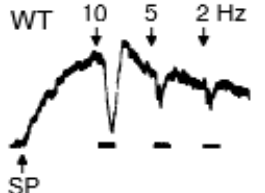

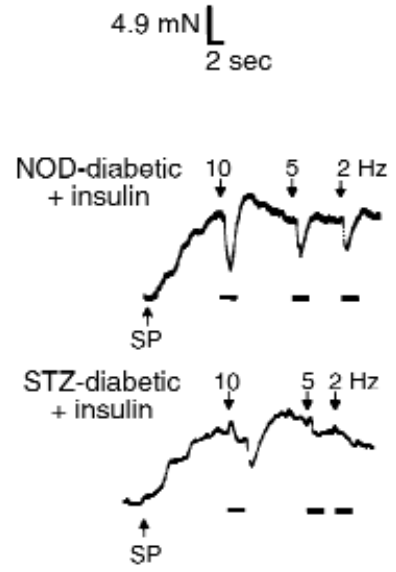

b

Figure 3

Pylori from diabetic mice lack NO-mediated NANC relaxation: reversal by insulin treatment. (a) EFS-evoked NO-mediated NANC relaxations are substantially reduced at 2,5 , and $10 \mathrm{~Hz}$ in $n \mathrm{NOS}^{-/-}$pylori compared with wild-type pylori. NOD-prediabetic pylori resembled the wild-type mice with maximal relaxation at $10 \mathrm{~Hz}$. NOD-diabetic pylori have nearly absent NANC relaxation at 2,5 , and $10 \mathrm{~Hz}$, resembling that of $n N O S^{-1-}$ pylori, whereas insulin treatment (1 week) of NOD-diabetic animals partially restores NANC relaxation. NANC relaxations in pylori from STZdiabetic mice are significantly reduced, similar to pylori from $n \mathrm{NOS}^{-/-}$mice, and insulin treatment (1 week) of STZ-diabetic animals restores NANC relaxation. In control experiments, we compared responses of wild-type pylori to EFS stimulation as 2, 5, and $10 \mathrm{~Hz}$ or in the reverse order 10,5 , and $2 \mathrm{~Hz}$, and we observed no apparent differences. The results shown are representative samples of five to ten pyloric preparations from different animals. (b) Quantification of NANC relaxation in response to EFS in diabetic pylori. Several pylori, representing the indicated groups of mice, were used to quantitatively analyze the degree of NANC relaxation in response to EFS. Data shown are the means ( \pm SEM) of several determinations for each group of mice: $n=10$ for wild-type; $n=8$ for $n N_{O S}^{-1-} ; n=5$ for NOD-prediabetic; $n=5$ for NOD-diabetic; $n=8$ for STZdiabetic; $n=5$ for insulin-treated NOD-diabetic $\left(\mathrm{NOD}_{\mathrm{i}}\right)$; and $n=8$ for insulin-treated STZ-diabetic $\left(\mathrm{STZ}_{\mathrm{i}}\right)$. ${ }^{\mathrm{A}} P<0.01$ for $n N O S^{-1-}$ and STZ-diabetic compared with wild-type specimens, for NOD-diabetic compared with NOD-prediabetic specimens, for insulin-treated NOD-diabetic specimens compared with NOD-diabetic specimens, and for insulin-treated STZ-diabetic specimens compared with STZ-diabetic samples.

hours after insulin therapy, whereas sham-operated animals had no significant change in their serum glucose levels (Figure 2b). We monitored gastric emptying in sham-operated STZ-diabetic, insulin-treated STZ-diabetic, and wild-type mice. The $t_{1 / 2}$ of gastric emptying in wild-type mice is 36 minutes compared with 60 minutes for STZ-diabetic animals (Figure 2c). After insulin treatment for 12 hours, we find only a modest increase in the gastric emptying rate with a $t_{1 / 2}$ of 54 minutes (Figure 2c). Thus hyperglycemia alone cannot account for the delayed gastric emptying observed in diabetic mice.

Given that delayed gastric emptying in $n \mathrm{NOS}^{-/-}$mice is associated with enlargement of the stomach, we monitored the size and weight of the stomach from mice with and without diabetes (Figure 2, $\mathrm{d}$ and e). By $30-32$ weeks of age (16-18 weeks after the onset of diabetes), NOD-diabetic mice develop gastric enlargement that resembles that of $n \mathrm{NOS}^{-/-}$specimens (Figure 2d). This enlargement is reflected in the weight of the stomachs obtained from NOD-diabetic animals (Figure 2e). The stomachs from STZ-diabetic mice (8 weeks after STZ treatment) often appear somewhat larger than wild-type specimens, but the weights of STZ-diabetic stomachs are not statistically different from those of wild-type specimens (Figure 2, $\mathrm{d}$ and e). Thus NODdiabetic mice develop gastric enlargement after 16-18 weeks of diabetes, similar to $n \mathrm{NOS}^{-/-}$mice.
Because delayed gastric emptying in $n \mathrm{NOS}^{-/-}$mice reflects loss of pyloric NO-dependent NANC transmission, we monitored NO-dependent NANC transmission in pylori derived from diabetic mice using ex vivo organ bath preparations. Pylori from NOD-diabetic and STZ-diabetic have responses to SP, Ach, and SNP that resemble wild-type pylori (data not shown). $n N^{-1-}$ pylori have a nearly complete loss of NANC relaxation at 2, 5, and $10 \mathrm{~Hz}$ EFS, whereas NOD-prediabetic pylori resemble wild-type mice with maximal relaxation at $10 \mathrm{~Hz}$ (Figure 3a). In contrast, NANC relaxation in NOD-diabetic and STZ-diabetic pylori is greatly reduced (Figure 3a). To quantify the loss of NOmediated relaxation, we analyzed data derived from the first NANC relaxation obtained in response to EFS (10 $\mathrm{Hz}$ ) from multiple pylori representing each group of animals (Figure 3b). Both STZ-diabetic and NOD-diabetic pylori have a dramatic reduction in NO-dependent NANC relaxation, mimicking $n N^{-1-}$ pylori (Figure $3 \mathrm{~b}$ ). Taken together these data suggest that delayed gastric emptying in diabetic mice reflects a loss of NOmediated pyloric relaxation.

$n N O S$ protein and $m R N A$ expression is lost in diabetic mice. Since diabetic and $n \mathrm{NOS}^{-/-}$mice have similar abnormal gastropyloric physiology, we wondered whether nNOS expression is altered in diabetic pylori. Thus, we examined the expression of nNOS protein by immunohis- 
Table 1

Body weights and serum glucose levels of experimental animals

\begin{tabular}{cccc}
\hline Treatment & $(n)$ & $\begin{array}{c}\text { Body weight } \\
(\mathrm{g})\end{array}$ & $\begin{array}{c}\text { Glucose level } \\
(\mathrm{mg} / \mathrm{dL})\end{array}$ \\
Wild-type & 50 & $29.5 \pm 0.3$ & $99 \pm 3$ \\
$n N O S^{-/-}$ & 30 & $31.1 \pm 0.4$ & $92 \pm 4$ \\
NOD-prediabetic & 50 & $23.3 \pm 0.3$ & $88 \pm 3$ \\
NOD-diabetic & 50 & $22.0 \pm 0.3$ & $232 \pm 5^{\mathrm{A}}$ \\
STZ-diabetic & 50 & $25.9 \pm 0.6$ & $388 \pm 11^{\mathrm{B}}$ \\
NOD-insulin implant & 30 & $22.9 \pm 0.3$ & $78 \pm 4^{\mathrm{C}}$ \\
STZ-insulin implant & 40 & $27.2 \pm 0.2$ & $91 \pm 4^{\mathrm{D}}$ \\
\hline
\end{tabular}

Data represent mean \pm SEM. $P<0.05$ compared with ANOD-prediabetic, ${ }^{B}$ wild-type, ${ }^{C N O D-d i a b e t i c, ~ a n d ~}{ }^{D S T Z}$-diabetic animals.

tochemistry and nNOS mRNA by in situ hybridization. Immunohistochemistry reveals discrete staining for nNOS in myenteric neurons in wild-type (Figure 4a) and NOD-prediabetic pylori (data not shown). Staining is absent in $\mathrm{NNOS}^{-/-}$mice (Figure 4a), confirming the antibody's specificity. nNOS staining is nearly abolished in NOD-diabetic and substantially reduced in STZ-diabetic pylori (Figure 4a). To quantify these changes, we determined the number of nNOS-positive neurons per high power field (hpf). nNOS-positive neurons are reduced about $65 \%$ in the STZ-diabetic pylori and by about $80 \%$ in the NOD-diabetic mice (Figure $4 \mathrm{~b})$. In situ hybridization reveals markedly decreased $n N O S$ mRNA expression in $n N O S^{-/-}$, NOD-diabetic, and STZ-diabetic pylori (Figure 5a). nNOS-positive nuclei are reduced by $78 \%$ in NOD-diabetic pylori and by $53 \%$ in STZ-diabetic pylori (Figure 5 b).
To ascertain whether the diabetes-induced depletion of nNOS expression is unique to the pylorus or is a general feature of all intestinal tissues, we monitored nNOS expression by Western blot in various intestinal tissues derived from NOD-prediabetic, NOD-diabetic, and insulin-treated NOD-diabetic mice (Figure 6). We find a pronounced depletion of nNOS in the pylorus, esophagus, and ileum (Figure 6). In the antrum and body (fundus) of the stomach, we find a partial depletion of nNOS expression in NOD-diabetic tissues (Figure 6), consistent with previous reports in diabetic rats $(26,27)$. A partial depletion of nNOS is also observed in the colon (Figure 6). We find no change in the expression of nNOS in the brain, suggesting that the depletion of nNOS in diabetes may be specific to the enteric nervous system (ENS). Thus, in diabetic mice, downregulation of nNOS occurs throughout the intestine, but is most pronounced in the pylorus, esophagus, and ileum.

Decreased nNOS protein and mRNA levels may reflect changes in nNOS expression or result from loss of the neurons that express nNOS. To determine whether loss of enteric neurons accounts for the decrease in nNOS immunoreactive neurons, we stained pyloric samples using antibodies to the neuronal markers, synaptophysin (SYN), microtubule-associated protein-2 (MAP-2), and neurofilament (NF; data not shown). MAP-2 and SYN immunoreactivity are not altered in $n \mathrm{NOS}^{-1-}$, NOD-diabetic, or STZ-diabetic pylori, indicating that neuronal loss does not account for depletion of nNOS expression (Figure 7). We also monitored vasoactive intestinal peptide (VIP) expression, as VIP and nNOS may colocalize within myenteric
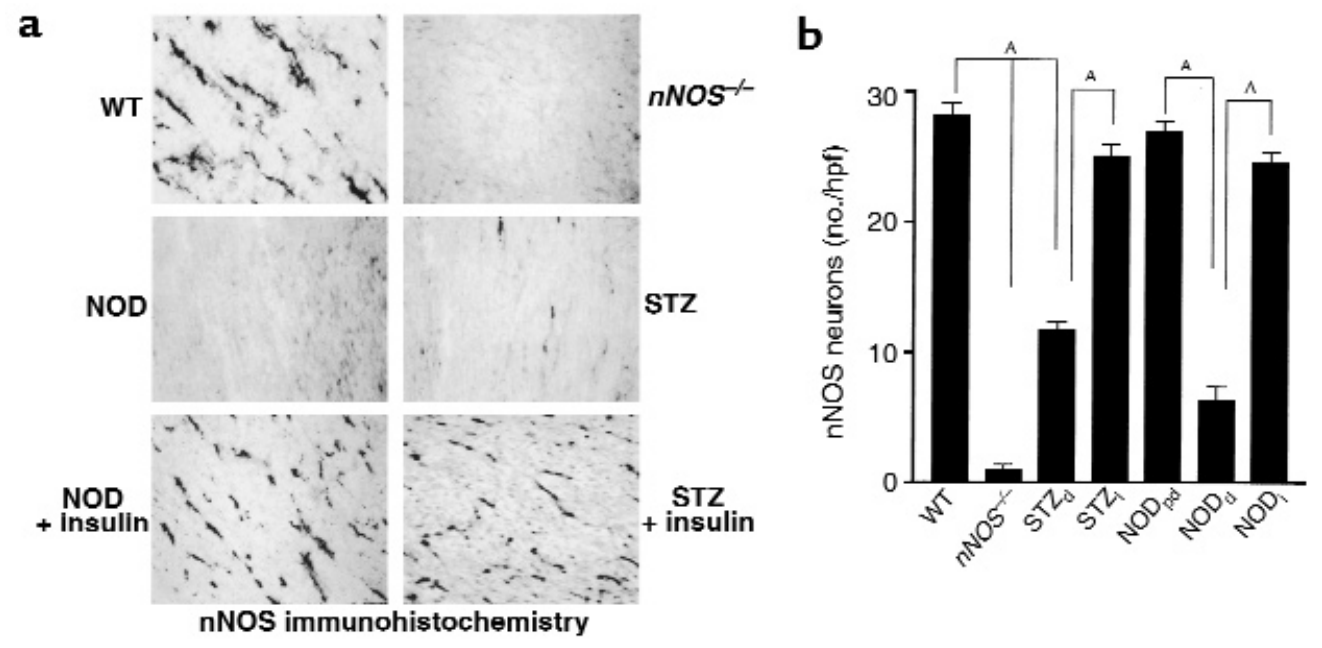

\section{Figure 4}

nNOS protein expression in the pyloric myenteric neurons is depleted in diabetic mice: reversal by insulin treatment. (a) Immunohistochemical analysis of $\mathrm{nNOS}$ protein expression. $\mathrm{nNOS}$ is present in wild-type but not $n \mathrm{NOS}^{-{ }^{--}}$pyloric myenteric neurons, whereas nNOS expression is lost in both NOD-diabetic and STZ-diabetic mice. Insulin treatment (1 week) of NOD-diabetic and STZ-diabetic animals reverses the loss of $\mathrm{nNOS}$ expression. (b) Quantification of nNOS protein expression. The number of $\mathrm{nNOS}$-expressing neurons per hpf $(\times 40)$ was determined, for ten microscopic fields, for each group of animals, with SEM as shown by the error bars. These results have been obtained in two separate experiments with four to six mice per group. ${ }^{A} P<0.01$ for $n N O S^{-1-}$ and STZ-diabetic samples compared with wild-type samples, for NOD-diabetic compared with NOD-prediabetic samples, for insulin-treated NOD-diabetic compared with NOD-diabetic samples, and for insulin-treated STZ-diabetic compared with STZ-diabetic specimens. 
neurons (49-51). VIP staining is preserved in both NOD-diabetic and STZ-diabetic pylori (Figure 7). These data indicate that the diminished nNOS does not reflect loss of myenteric neurons.

Sildenafil reverses delayed gastric emptying in diabetic mice. Conceivably, the expression of several proteins is reduced by the insulin depletion that occurs in diabetic animals. nNOS mediates smooth muscle relaxation through the activation of cGMP production by soluble guanylate cyclase in smooth muscle cells. Some disorders of NOdependent smooth muscle relaxation, such as impotence, can be treated by inhibition of the cGMP specific phosphodiesterase-5 (PDE5) that breaks down cGMP $(52,53)$. To determine whether the loss of nNOS accounts for delayed gastric emptying, we used sildenafil. This was used because the PDE5 is enriched in the pylorus (54). Inhibition of PDE5 allows the accumulation of cGMP in the presence of lower NO levels. We wondered whether treatment of diabetic animals with sildenafil would accelerate gastric emptying. Accordingly, we treated STZ-diabetic and NOD-diabetic mice with sildenafil $(1 \mathrm{mg} / \mathrm{kg})$ and monitored gastric emptying. Sildenafil reverses the delayed gastric emptying of both STZ-diabetic and NOD-diabetic mice with $t_{1 / 2}$ for gastric emptying of 30 and 36 minutes for sildenafil-treated STZ-diabetic and sildenafil-treated NOD-diabetic animals, respectively (Figure 8). These data implicate impaired NO signaling as the mechanism through which delayed gastric emptying develops in diabetic mice.

$n N O S$ expression and NO-dependent NANC relaxation are restored by insulin treatment. Both NOD-diabetic and STZ-diabetic mice have elevated serum glucose with low insulin levels. We corrected these abnormalities by treat- ment with an implantable insulin device (Table 1). After 1 week of insulin treatment, gastric emptying in both NOD-diabetic and STZ-diabetic mice is restored to normal (Figure 9a). Insulin treatment also restores EFSinduced NANC relaxation in pylori from insulin-treated NOD-diabetic or STZ-diabetic animals (Figure 3, b and c). The restorative effect of insulin on EFS-induced relaxations from insulin-treated NOD-diabetic pylori was greater than that observed in insulin-treated STZdiabetic pylori. This finding may reflect the more dramatic loss of nNOS expression observed in the NODdiabetic mice (Figures $4 \mathrm{~b}$ and $5 \mathrm{~b}$ ).

Insulin treatment is likely to alter the expression of numerous genes. To determine whether the induction of nNOS expression mediates the effect of insulin on gastric emptying, we monitored gastric emptying at 30 minutes in insulin-treated STZ-diabetic and insulintreated NOD-diabetic mice after administration of the nNOS inhibitor 7-NI. 7-NI reverses the restoration of normal gastric emptying in insulin-treated diabetic mice (Figure 9b), indicating that nNOS catalytic activity mediates the effect of insulin treatment on gastric emptying. As insulin restores NANC relaxation in diabetic pylori, we tested NANC relaxation in the presence of $0.1 \mathrm{mM}$ 7-NI. Under these conditions, NANC relaxation is completely blocked (data not shown), indicating that nNOS expression also accounts for the restorative effects of insulin on pyloric relaxation.

Insulin treatment returns nNOS protein expression in NOD-diabetic and STZ-diabetic pylori to near normal levels (Figure 4, a and b). In situ hybridization reveals that insulin treatment also substantially restores $n N O S$ mRNA in both NOD-diabetic and STZ-
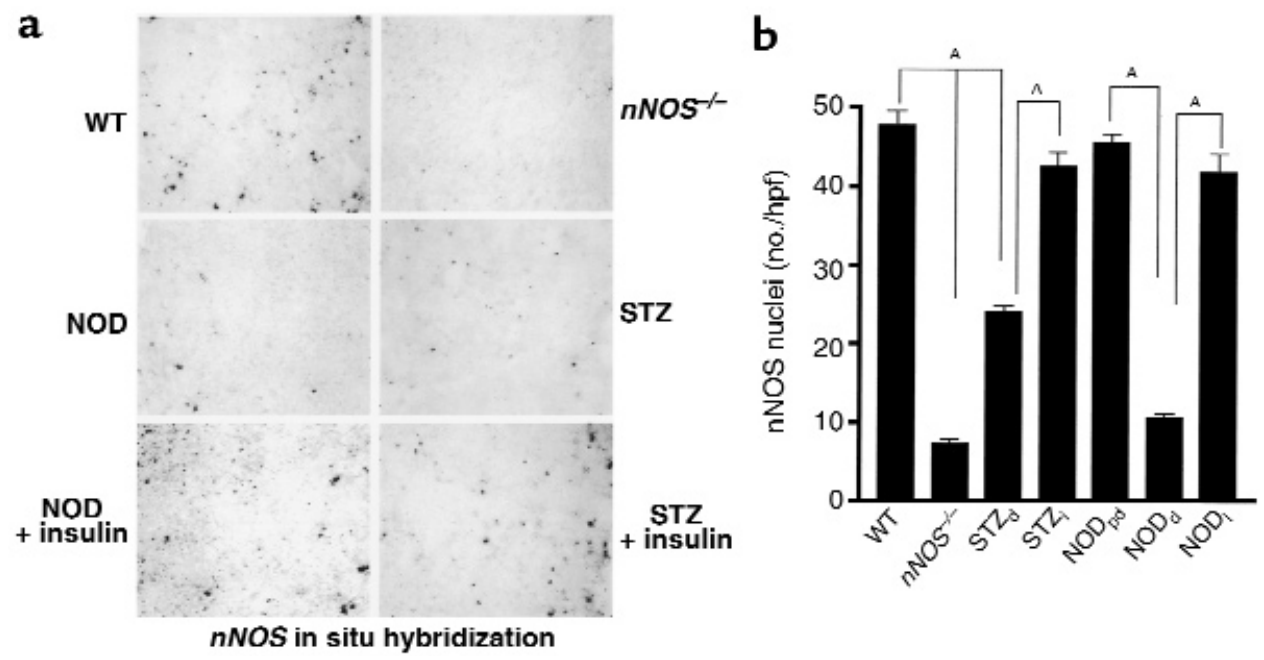

Figure 5

$n N O S$ mRNA expression in the pyloric myenteric neurons is depleted in diabetic mice: reversal by insulin treatment. (a) In situ hybridization analysis of nNOS expression. nNOS mRNA expression is present in wild-type and depleted $n N O S^{-1-}$ pyloric myenteric neurons, whereas $n N O S$ mRNA expression is significantly decreased in both NOD-diabetic and STZ-diabetic mice. (b) Quantification of nNOS mRNA expression. The number of positive nuclei for $n N O S$ mRNA per hpf was determined for ten microscopic fields, for each treatment group, with SEM as shown by the error bars. These results have been obtained in two separate experiments with four to six mice per group. ${ }^{A} P<0.01$ for $n N O S^{-1}$ and STZ-diabetic samples compared with wild-type samples, for NOD-diabetic compared with NOD-prediabetic samples, for insulin-t reated NOD-diabetic compared with NOD-diabetic samples, and for insulin-treated STZ-diabetic compared with STZ-diabetic specimens. 


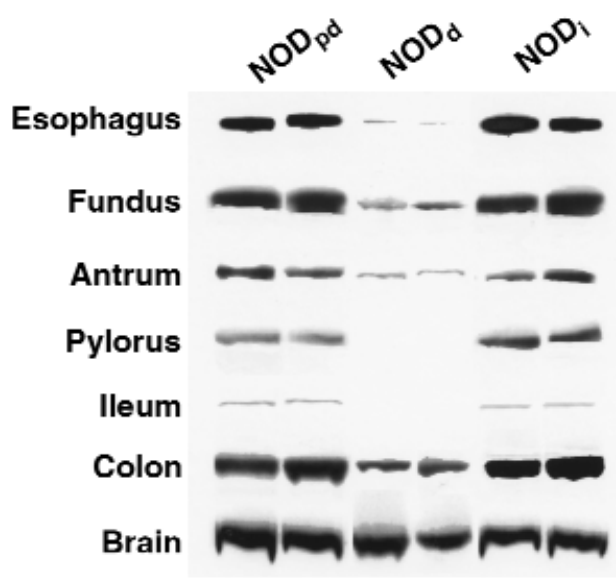

Figure 6

nNOS protein is depleted throughout the intestine in NOD mice: reversal by insulin. Western blot analysis of $\mathrm{nNOS}$ protein expression was performed using samples from several regions of intestine derived from NOD-prediabetic, NOD-diabetic, and insulin-treated NOD-diabetic mice. nNOS protein is nearly completely depleted in the pylorus, esophagus, and ileum, with only partial depletion in other intestinal regions. There is no apparent change in nNOS expression in the brain. Insulin treatment (1 week) completely reverses the loss of nNOS protein. The results are shown in duplicate and are representative of six animals analyzed for each group.

diabetic pylori (Figure 5, a and b). The depletion of nNOS expression throughout the intestine is fully reversible by insulin, although diabetes induces only a partial depletion of nNOS protein in some intestinal tissues (Figure 6).

\section{Discussion}

Gastropathy is an important cause of morbidity for diabetic patients, although the etiology of this syndrome is obscure. Using two models of diabetes in mice, we now report that diabetic mice develop selective depletion of nNOS protein and mRNA and delayed gastric emptying in conjunction with a loss of NOmediated NANC neurotransmission that mimics the phenotype of mice harboring a genomic deletion of $n N O S$. Our findings are consistent with recent reports of decreased nNOS expression and NANC relaxation in the gastric specimens of diabetic rats (25-27). Two lines of evidence support nNOS deficiency as causal in diabetic gastropathy in these mouse models. First, sildenafil, a potent and selective PDE5 inhibitor that augments the effects of reduced NO levels, is able to restore gastric emptying in diabetic mice. Second, treatment of diabetic animals with insulin restores myenteric nNOS protein and mRNA, restores NO-mediated NANC neurotransmission, and reverses delayed gastric emptying. Thus, delayed gastric emptying in diabetic mice results from a reversible loss of nNOS expression within myenteric neurons that can be reversed with sildenafil.

Gastric emptying results from the coordinated activity of the proximal stomach (fundus), antrum, pylorus, and duodenum (10). Loss of fundal relaxation in $n \mathrm{NOS}^{-/-}$or diabetic mice would be expected to accelerate gastric emptying, whereas loss of pyloric or duodenal relaxation may delay gastric emptying. In both $n \mathrm{NOS}^{-/-}$and diabetic mice, the loss of nNOS is associated with delayed gastric emptying consistent with a major physiological effect on pyloric function. This conclusion is supported by our findings of more pronounced depletion of nNOS in the pylorus compared with the fundus and antrum and with the anatomic changes observed in these animals. Interestingly, in patients with recently diagnosed diabetes, some investigators have described accelerated gastric emptying (39, $55,56)$. These findings may reflect predominant loss of nNOS in the fundus or antrum in early diabetes. In our experiments, we do not detect accelerated gastric emptying. Our studies have only examined gastric emptying after 8 or 16 weeks of diabetes for the STZ-diabetic and NOD-diabetic animals, respectively. Perhaps accelerated gastric emptying would be detectable sooner after the onset of diabetes in mice. Alternatively, accelerated gastric emptying in early diabetic gastropathy may be more common in type II diabetes (48) or may be more prominent in humans compared with mice.

Molecular mechanisms regulating changes in expression of nNOS are unclear. nNOS expression is dramatically increased in spinal cord motor neurons after lesions of the ventral root $(57,58)$ and in the retina after pterygopalatine parasympathetic denervation (59). The insulin-induced reversal of nNOS loss in diabetic mice suggests that insulin or IGFs may regulate the expression of nNOS in these systems. Alternatively, glucose, which is also known to affect gene expression, may directly or indirectly influence nNOS expression. Interestingly, glucoresponsive neurons within the ENS have recently been reported (60).

Although nNOS expression was substantially reduced in diabetic mice in the ENS, we found no significant changes in nNOS levels in the central nervous system of these animals. We speculate that alternative

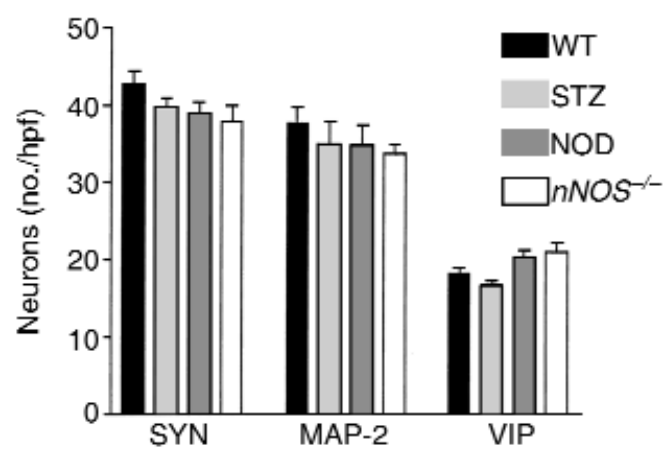

\section{Figure 7}

Pylori of diabetic mice have a loss of nNOS expression without a loss of neurons. Myenteric neurons were quantified by counting the number of positive neurons per hpf. No change in expression of SYN, MAP2, or VIP was observed for either STZ-diabetic or NOD-diabetic mice. The data shown are the means ( \pm SEM) of determinations from at least ten microscopic fields, with the experimenter blinded to the treatment condition of the animals from which the histological sections were derived. 


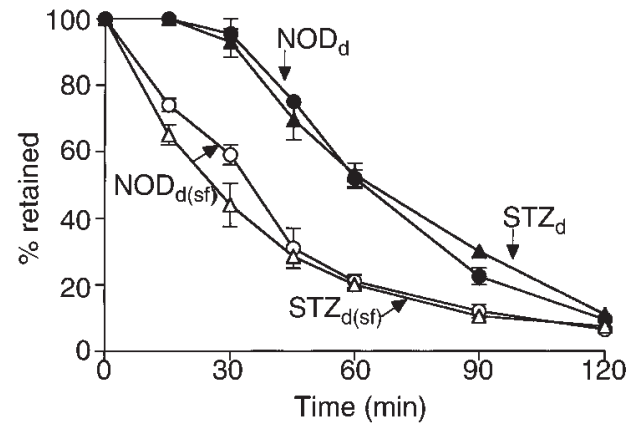

Figure 8

PDE5 inhibition reverses delayed gastric emptying in diabetic mice. NOD-diabetic and STZ-diabetic mice were treated with sildenafil (sf), as described in Methods, 20 minutes before determining gastric emptying. The data shown are the means ( \pm SEM) of quadruplicate determinations representing four animals for each data point. Sildenafil treatment of diabetic animals reverses delayed gastric emptying in diabetic animals.

promoter usage, which is particularly pronounced and tissue specific in the case of $n N O S$ (61-65), might account for the selective downregulation of $\mathrm{nNOS}$ observed in the ENS of diabetic animals. The apparently complete depletion of nNOS in the pylorus, esophagus, and ileum may reflect the use of a single, insulin- or glucose-sensitive, promoter in these tissues, whereas the partial depletion observed in the antrum, fundus, and colon may reflect the use of an additional glucose/insulin insensitive promoter(s).

Diabetic patients manifest motility disturbances in the small intestine and colon as well as the stomach (5, $6)$, and recent evidence suggests that NO mechanisms regulate human small intestinal motility (66). In diabetes, diarrhea may reflect diminished small intestinal motility allowing bacteria overgrowth, whereas constipation may result from poor motility in the colon. Perhaps the decreased nNOS expression we observe in intestinal tissues other than the pylorus contributes to other diabetic gastrointestinal syndromes. Interestingly, diabetic gastropathy and other diabetic gastrointestinal syndromes may worsen when patients are not taking insulin or have poor glucose control associated with illness $(5,6,67)$. Symptomatic improvement often follows resumption of insulin therapy or improved control of serum glucose levels. Accordingly, reversible decreases in nNOS expression, as reported here, may underlie the relapsing and remitting clinical course associated with diabetic gastrointestinal syndromes.

Other gastrointestinal disorders, unrelated to diabetes, may also result from dysregulation of nNOS in myenteric neurons. For example, pylori from infants with hypertrophic pyloric stenosis display a selective loss of nNOS $(16,17)$. In this condition, loss of nNOS leads to pyloric hypertrophy and a complete blockade of gastric emptying. In the esophagus, loss of nNOSexpressing neurons is associated with dysfunction of the lower esophageal sphincter resulting in achalasia
(68-70). Functional bowel disorders, including irritable bowel syndrome and functional dyspepsia, affect a large group of patients who may have motility disturbances $(71,72)$. Recent reports suggest that delayed gastric emptying is common in these patients $(73,74)$, although whether NO-dependent mechanisms play a role remains to be determined.

Our findings have therapeutic implications. Currently, the major drugs used in treating diabetic gastropathy include domperidone, metoclopramide, cisapride, and erythromycin $(5,6)$. These drugs act by increasing stomach contractions. Their limited clinical utility may reflect the finding that abnormalities in diabetic gastropathy are primarily in the NANC relaxation rather than the contractile component of gastropyloric function. Drugs that enhance the effect of NO, or of its effector, cGMP, would presumably cause pyloric relaxation. We found that treatment of diabetic mice with the PDE5 inhibitor sildenafil reverses delayed gastric emptying. This finding is consistent with a recent study demonstrating enrichment of PDE5 in the pylorus (54).
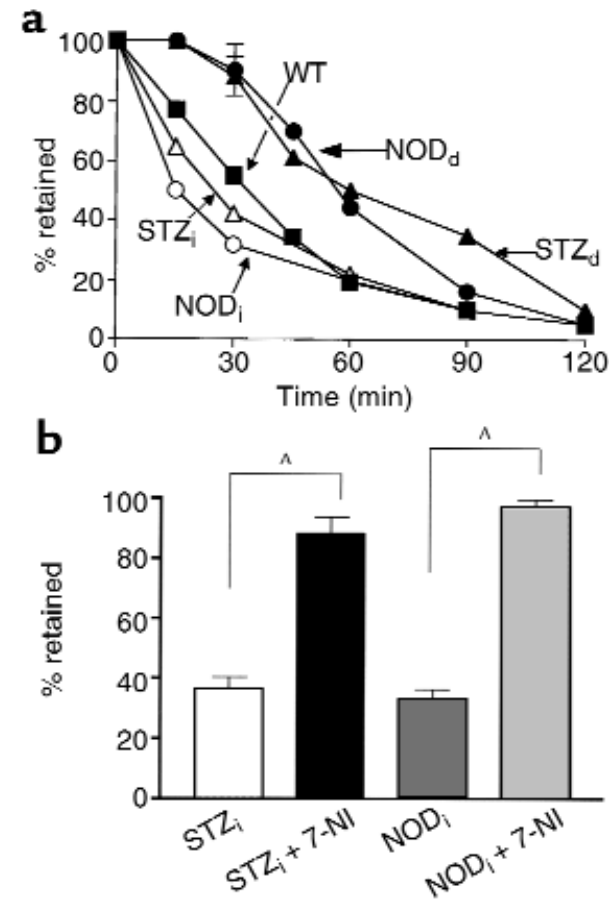

\section{Figure 9}

Insulin treatment reverses delayed gastric emptying. (a) Insulin treatment (1 week) of STZ-diabetic and NOD-diabetic mice reverses delayed gastric emptying ( $20 \%$ dextrose). The data shown are the means ( \pm SEM) of quadruplicate determinations representing four animals for each data point. (b) Inhibition of nNOS with 7-NI delays gastric emptying in insulin-treated diabetic mice. Diabetic mice were treated with insulin (1 week) and subsequently treated with the nNOS inhibitor 7-NI ( $50 \mathrm{mg} / \mathrm{kg})$ as described in Methods. Gastric emptying was measured, and mice were sacrificed at 30 minutes. Data shown are means $( \pm$ SEM) of five determinations reflecting five animals in each group. ${ }^{A} P<0.01$ for $7-\mathrm{NI}$-injected, insulin-treated NOD-diabetic animals compared with insulin-treated NOD-diabetic mice and for 7-NI-injected, insulin-treated STZ-diabetic animals compared with insulin-treated STZ-diabetic animals. 
Interestingly, a recent report suggests that sildenafil can inhibit esophageal motility in patients with achalasia (74). Thus, PDE5-selective inhibitors, such as sildenafil, may be effective in the treatment of diabetic gastropathy and related conditions.

\section{Acknowledgments}

This work was supported by U.S. Public Health Service grant DA-00266, Research Scientist Award DA-00074 (to S.H. Snyder), and a National Institute of Mental Health Individual National Research Service Award to C.C. Watkins. C.D. Ferris has a Howard Hughes Fellowship for Physicians. The authors thank L. Hester for expert technical assistance, L. Schramm for thoughtful discussions, and A. Burnett, S. Sezen, and J. Crone for assistance with physiological experiments.

1. Porte, D., Jr., and Halter, J.B. 1999. The clinical syndrome of diabetes mellitus. In Diabetic neuropathy. P.J. Dyck and P.K. Thomas, editors. W.B. Saunders Co. Philadelphia, Pennsylvania, USA. 1-28.

2. Foster, D.W. 1998. Diabetes mellitus. In Harrison's principles of internal medicine. A.S. Fauci et al., editors. McGraw-Hill. New York, New York, USA. 2060-2081

3. Feldman, M., and Schiller, L.R. 1983. Disorders of gastrointestinal motility associated with diabetes mellitus. Ann. Intern. Med. 98:378-384.

4. Abrahamsson, H. 1995. Gastrointestinal motility disorders in patients with diabetes mellitus. J. Intern. Med. 237:403-409.

5. Koch, K.L. 1999. Diabetic gastropathy: gastric neuromuscular dysfunction in diabetes mellitus: a review of symptoms, pathophysiology, and treatment. Dig. Dis. Sci. 44:1061-1075.

6. Verne, G.N., and Sninsky, C.A. 1998. Diabetes and the gastrointestinal tract. Gastroenterol. Clin. North Am. 27:861-874.

7. Kassander, P. 1958. Asymptomatic gastric retention in diabetes (gastroparesis diabeticorum). Ann. Intern. Med. 48:797-812.

8. Hoogerwerf, W.A., Pasricha, P.J., Kalloo, A.N., and Schuster, M.M. 1999 Pain: the overlooked symptom in gastroparesis. Am. J. Gastroenterol. 94:1029-1033.

9. Tougas, G., et al. 1992. Relation of pyloric motility to pyloric opening and closure in healthy subjects. Gut. 33:466-471.

10. Horowitz, M., Dent, J., Fraser, R., Sun, W., and Hebbard, G. 1994. Role and integration of mechanisms controlling gastric emptying. Dig. Dis. Sci. 39(Suppl.):7S-13S.

11. Mearin, F., Camilleri, M., and Malagelada, J.R. 1986. Pyloric dysfunction in diabetics with recurrent nausea and vomiting. Gastroenterology. 90:1919-1925.

12. Tomita, R., Tanjoh, K., Fujisaki, S., and Fukuzawa, M. 1999. The role of nitric oxide (NO) in the human pyloric sphincter. Hepatogastroenterology. 46:2999-3003

13. Stark, M.E., and Szurszewski, J.H. 1992. Role of nitric oxide in gastrointestinal and hepatic function and disease. Gastroenterology. 103:1928-1949.

14. Bult, H., et al. 1990. Nitric oxide as an inhibitory non-adrenergic noncholinergic neurotransmitter. Nature. 345:346-347.

15. Huang, P.L., Dawson, T.M., Bredt, D.S., Snyder, S.H., and Fishman, M.C. 1993. Targeted disruption of the neuronal nitric oxide synthase gene. Cell. 75:1273-1286.

16. Vanderwinden, J.M., Mailleux, P., Schiffmann, S.N., Vanderhaeghen, J.J., and De Laet, M.H. 1992. Nitric oxide synthase activity in infantile hypertrophic pyloric stenosis. N. Engl. J. Med. 327:511-515.

17. Chung, E., et al. 1996. Genetic evidence for the neuronal nitric oxide synthase gene (NOS1) as a susceptibility locus for infantile pyloric stenosis. Am. J. Hum. Genet. 58:363-370.

18. Sun, W.M., et al. 1996. Effects of glyceryl trinitrate on the pyloric motor response to intraduodenal triglyceride infusion in humans. Eur. J. Clin. Invest. 26:657-664.

19. Sun, W.M., et al. 1998. Effects of nitroglycerin on liquid gastric emptying and antropyloroduodenal motility. Am.J. Physiol. 275:G1173-G1178.

20. Konturek, J.W., Thor, P., and Domschke, W. 1995. Effects of nitric oxide on antral motility and gastric emptying in humans. Eur. J. Gastroenterol. Hepatol. 7:97-102.

21. Konturek, J.W., Fischer, H., Gromotka, P.M., Konturek, S.J., and Domschke, W. 1999. Endogenous nitric oxide in the regulation of gastric secretory and motor activity in humans. Aliment. Pharmacol. Ther. 13:1683-1691.

22. Anvari, M., Paterson, C.A., and Daniel, E.E. 1998. Role of nitric oxide mechanisms in control of pyloric motility and transpyloric flow of liquids in conscious dogs. Dig. Dis. Sci. 43:506-512.

23. Plourde, V., Quintero, E., Suto, G., Coimbra, C., and Tache, Y. 1994. Delayed gastric emptying induced by inhibitors of nitric oxide synthase in rats. Eur. J. Pharmacol. 256:125-129.

24. Orihata, M., and Sarna, S.K. 1994. Inhibition of nitric oxide synthase delays gastric emptying of solid meals. J. Pharmacol. Exp. Ther. 271:660-670.

25. Jenkinson, K.M., and Reid, J.J. 1995. Effect of diabetes on relaxations to non-adrenergic, non-cholinergic nerve stimulation in longitudinal muscle of the rat gastric fundus. Br. J. Pharmacol. 116:1551-1556.

26. Wrzos, H.F., Cruz, A., Polavarapu, R., Shearer, D., and Ouyang, A. 1997. Nitric oxide synthase (NOS) expression in the myenteric plexus of streptozotocin-diabetic rats. Dig. Dis. Sci. 42:2106-2110.

27. Takahashi, T., Nakamura, K., Itoh, H., Sima, A.A., and Owyang, C. 1997. Impaired expression of nitric oxide synthase in the gastric myenteric plexus of spontaneously diabetic rats. Gastroenterology. 113:1535-1544.

28. Agarwal, M.K. 1980. Streptozotocin: mechanisms of action: proceedings of a workshop held on 21 June, 1980, Washington, DC. FEBS Lett. 120:1-3.

29. Kuo, W.H., Wadwa, K.S., and Ferris, C.D. 1998. Cephalosporin antibiotics accelerate gastric emptying in mice. Dig. Dis. Sci. 43:1690-1694.

30. Schaeren-Wiemers, N., and Gerfin-Moser, A. 1993. A single protocol to detect transcripts of various types and expression levels in neural tissue and cultured cells: in situ hybridization using digoxigenin-labelled cRNA probes. Histochemistry. 100:431-440.

31. Eliasson, M.J., Blackshaw, S., Schell, M.J., and Snyder, S.H. 1997. Neuronal nitric oxide synthase alternatively spliced forms: prominent functional localizations in the brain. Proc. Natl. Acad. Sci. USA. 94:3396-3401.

32. Mashimo, H., He, X.D., Huang, P.L., Fishman, M.C., and Goyal, R.K. 1996. Neuronal constitutive nitric oxide synthase is involved in murine enteric inhibitory neurotransmission. J. Clin. Invest. 98:8-13.

33. Li, C.G., and Rand, M.J. 1990. Nitric oxide and vasoactive intestinal polypeptide mediate non-adrenergic, non-cholinergic inhibitory transmission to smooth muscle of the rat gastric fundus. Eur. J. Pharmacol. 191:303-309.

34. Lefebvre, R.A., Smits, G.J., and Timmermans, J.P. 1995. Study of NO and VIP as non-adrenergic non-cholinergic neurotransmitters in the pig gastric fundus. Br. J. Pharmacol. 116:2017-2026.

35. Grunewald, K.K., and Tucker, T.J. 1985. Gastric emptying in exercised mice. Comp. Biochem. Physiol. A. 80:173-175.

36. Horowitz, M., et al. 1991. Relationships between oesophageal transit and solid and liquid gastric emptying in diabetes mellitus. Eur. J. Nucl. Med. 18:229-234.

37. Horowitz, M., et al. 1989. Gastric and oesophageal emptying in patients with type 2 (non-insulin- dependent) diabetes mellitus. Diabetologia. 32:151-159.

38. Kong, M.F., Macdonald, I.A., and Tattersall, R.B. 1996. Gastric emptying in diabetes. Diabet. Med. 13:112-119.

39. Delovitch, T.L., and Singh, B. 1997. The nonobese diabetic mouse as a model of autoimmune diabetes: immune dysregulation gets the NOD. Immunity. 7:727-738.

40. Jones, K.L., et al. 1999. The effect of erythromycin on gastric emptying is modified by physiological changes in the blood glucose concentration. Am. J. Gastroenterol. 94:2074-2079.

41. MacGregor, I.L., Gueller, R., Watts, H.D., and Meyer, J.H. 1976. The effect of acute hyperglycemia on gastric emptying in man. Gastroenterology. 70:190-196

42. Schvarcz, E., et al. 1997. Physiological hyperglycemia slows gastric emptying in normal subjects and patients with insulin-dependent diabetes mellitus. Gastroenterology. 113:60-66.

43. Samsom, M., et al. 1997. Gastrointestinal motor mechanisms in hyperglycaemia induced delayed gastric emptying in type I diabetes mellitus. Gut. 40:641-646.

44. Hebbard, G.S., Samsom, M., Sun, W.M., Dent, J., and Horowitz, M. 1996. Hyperglycemia affects proximal gastric motor and sensory function during small intestinal triglyceride infusion. Am. J. Physiol. 271:G814-G819.

45. Fraser, R., Horowitz, M., and Dent, J. 1991. Hyperglycaemia stimulates pyloric motility in normal subjects. Gut. 32:475-478.

46. Fraser, R.J., et al. 1990. Hyperglycaemia slows gastric emptying in type 1 (insulin-dependent) diabetes mellitus. Diabetologia. 33:675-680.

47. Fraser, R., Horowitz, M., Maddox, A., and Dent, J. 1993. Organization of antral, pyloric and duodenal motility in patients with gastroparesis. Journal of Gastrointestinal Motility. 5:167-175.

48. Aimi, Y., et al. 1993. Histochemical localization of nitric oxide synthase in rat enteric nervous system. Neuroscience. 53:553-560.

49. Costa, M., et al. 1992. Projections and chemical coding of neurons with immunoreactivity for nitric oxide synthase in the guinea-pig small intestine. Neurosci. Lett. 148:121-125.

50. Berezin, I., Snyder, S.H., Bredt, D.S., and Daniel, E.E. 1994. Ultrastructural localization of nitric oxide synthase in canine small intestine and 
colon. Am. J. Physiol. 266:C981-C989.

51. Corbin, J.D., and Francis, S.H. 1999. Cyclic GMP phosphodiesterase-5: target of sildenafil. J. Biol. Chem. 274:13729-13732.

52. Goldstein, I., et al. 1998. Oral sildenafil in the treatment of erectile dysfunction. Sildenafil Study Group. N. Engl. J. Med. 338:1397-1404.

53. Kotera, J., et al. 1998. Novel alternative splice variants of cGMP-binding cGMP-specific phosphodiesterase. J. Biol. Chem. 273:26982-26990.

54. Lipp, R.W., et al. 1997. Evidence of accelerated gastric emptying in longstanding diabetic patients after ingestion of a semisolid meal. J. Nucl. Med. 38:814-818.

55. Phillips, W.T., Schwartz, J.G., and McMahan, C.A. 1992. Rapid gastric emptying of an oral glucose solution in type 2 diabetic patients. J. Nucl. Med. 33:1496-1500.

56. Zhang, X., et al. 1993. Nitric oxide synthase-like immunoreactivity in lumbar dorsal root ganglia and spinal cord of rat and monkey and effect of peripheral axotomy. J. Comp. Neurol. 335:563-575.

57. Wu, W., et al. 1994. Neuronal nitric oxide synthase is induced in spinal neurons by traumatic injury. Neuroscience. 61:719-726.

58. Yamamoto, R., Bredt, D.S., Dawson, T.M., Snyder, S.H., and Stone, R.A. 1993. Enhanced expression of nitric oxide synthase by rat retina following pterygopalatine parasympathetic denervation. Brain Res. 631:83-88.

59. Liu, M., Seino, S., and Kirchgessner, A.L. 1999. Identification and characterization of glucoresponsive neurons in the enteric nervous system. J. Neurosci. 19:10305-10317.

60. Brenman, J.E., Xia, H., Chao, D.S., Black, S.M., and Bredt, D.S. 1997. Regulation of neuronal nitric oxide synthase through alternative transcripts. Dev. Neurosci. 19:224-231.

61. Hall, A.V., et al. 1994. Structural organization of the human neuronal nitric oxide synthase gene (NOS1). J. Biol. Chem. 269:33082-33090.

62. Wang, Y., and Marsden, P.A. 1995. Nitric oxide synthases: gene structure and regulation. Adv. Pharmacol. 34:71-90.

63. Wang, Y., et al. 1999. RNA diversity has profound effects on the transla- tion of neuronal nitric oxide synthase. Proc. Natl. Acad. Sci. USA. 96:12150-12155.

64. Wang, Y., Newton, D.C., and Marsden, P.A. 1999. Neuronal NOS: gene structure, mRNA diversity, and functional relevance. Crit. Rev. Neurobiol. 13:21-43.

65. Russo, A., Fraser, R., Adachi, K., Horowitz, M., and Boeckxstaens, G. 1999. Evidence that nitric oxide mechanisms regulate small intestinal motility in humans. Gut. 44:72-76.

66. Malcolm, A., and Camilleri, M. 1999. Assessment of gastrointestinal function. In Diabetic neuropathy. P.J. Dyck and P.K. Thomas, editors. W.B. Saunders Co. Philadelphia, Pennsylvania, USA. 211-221.

67. Pasricha, P.J., Huang, R.L., Rai, R., and Ferris, C.D. 1997. Achalasia and other motor disorders. In Gastrointestinal disease: an endoscopic approach. A.J. Dimarino and S.B. Benjamin, editors. Blackwell Science Inc. Malden, Massachusetts, USA. 205-240.

68. De Giorgio, R., et al. 1999. Esophageal and gastric nitric oxide synthesizing innervation in primary achalasia. Am. J. Gastroenterol. 94:2357-2362.

69. Mearin, F., et al. 1993. Patients with achalasia lack nitric oxide synthase in the gastro-oesophageal junction. Eur. J. Clin. Invest. 23:724-728.

70. Maxwell, P.R., Mendall, M.A., and Kumar, D. 1997. Irritable bowel syndrome. Lancet. 350:1691-1695.

71. Lynn, R.B., and Friedman, L.S. 1993. Irritable bowel syndrome. N. Engl. J. Med. 329:1940-1945.

72. Evans, P.R, Bak, Y.T, Shuter, B., Hoschl, R, and Kellow, J.E. 1997. Gastroparesis and small bowel dysmotility in irritable bowel syndrome. Dig. Dis. Sci. 42:2087-2093.

73. Pfaffenbach, B., Adamek, R.J., Bartholomaus, C., and Wegener, M. 1997. Gastric dysrhythmias and delayed gastric emptying in patients with functional dyspepsia. Dig. Dis. Sci. 42:2094-2099.

74. Bortolotti, M., Mari, C., Lopilato, C., Porrazzo, G., and Miglioli, M. 2000. Effects of sildenafil on esophageal motility of patients with idiopathic achalasia. Gastroenterology. 118:253-257. 